\title{
TRADISI OMED-OMEDAN SEBAGAI PENDIDIKAN KARAKTER BAGI TERUNA-TERUNI BANJAR KAJA DALAM RANGKAIAN HARI RAYA NYEPI DI KELURAHAN SESETAN DENPASAR SELATAN
}

\author{
Ni Made Yuni Artini dan Ida Bagus Nyoman Wartha \\ Program Studi Pendidikan Sejarah Fakultas Keguruan dan Ilmu Pendidikan \\ Universitas Mahasaraswati Denpasar
}

\begin{abstract}
Balinese always preserve cultural traditions as the inheritance of their ancestors. Omed-omedan tradition is a unique and rare tradition since such tradition cannot be encountered in other areas. Therefore, it is interesting to be discussed in a paper. This reseacrh was aimed at finding out: How is the process of implementation of Omed-omedan tradition at Banjar Kaja Kelurahan Sesetan, South Denpasar Sub-District, Denpasar City?, What is the relationship between Omed-omedan tradition and the series of Nyepi Holiday at Banjar Kaja Kelurahan Sesetan, South Denpasar Sub-District Denpasar City? What is the meaning of Omed-omedan tradition for the people at Banjar Kaja Kelurahan Sesetan, South Denpasar Sub-District, Denpasar City? The theoretical bases applied in this research are 1). Culture, 2). Religious systems, 3). Society. The results of the research show that the implementation of Omed-omedan Tradition must be conducted as it relates to Ida Bhatara Sesuhunan at in Banjar Kaja Sesetan temple, which is believed to be able to provide safety for His people, in addition, Omedomedan tradition is also an event of Masima Krama (visit and forgive each other) to welcome Caka New Year (Nyepi Holiday). The conclusions of this research are 1). Omed-omedan tradition is Purwa Dresta, namely a religious custom and it is not allowed if it is not conducted because if it is not conducted, it is believed it would lead to the undesirable things, 2). In its performance, Omed-omedan tradition is an event of Masima Krama in order to welcome Caka New Year, 3). The meaning of this Omed-omedan tradition is as a devotion to Ida Bhatara Sesuhunan, as by always conducting this tradition, the members of Banjar Kaja Sesetan are believed to always have His protection.
\end{abstract}

Keywords: Omed-omedan Tradition, Nyepi Holiday, Traditional Village

\begin{abstract}
ABSTRAK
Masysrakat Bali selalu menjaga tradisi dan budayanya sebagai warisan dari para leluhur. Tradisi Omed-omedan merupakan tradisi yang unik dan langka karena tidak dapat dijumpai di daerah lain. Untuk itu, sangatlah menarik untuk dikaji dalam bentuk tulisan. Penelitian ini bertujuan untuk: mengetahui bagaimana proses implementasi Omed-omedan di Banjar Kaja, Kelurahan Sesetan, Kecamatan Denpasar Selatan dan mengetahui makna dibalik pelaksanaan Omedomedan bagi masyarakat Banjar Kaja Sesetan. Landasan teoretis yang digunakan dalam penelitian kali ini adalah landasan 1). Budaya, 2) sistem Keagamaan, 3). Masyarakat. Hasil penelitian ini mengungkap bahwa pelaksanaan tradisi Omedomedanberkaitan dengan Ida Bhatara Sesuhunan di Pura Banjar Kaja Sesetan,
\end{abstract}


yang dipercaya mampu melindungi masyarakat, disamping itu, Omed-omedan merupakan tradisi Mesima Krama (saling mengunjungi dan memaafkan sesama) dalam rangka menyambut Hari Raya Nyepi (Tahun Baru Caka). Simpulan dari penelitian ini adalah 1). Tradisi Omed-omedan adalah Purwa Dresta, yaitu tradisi keagamaan yang jika tidak dilaksanakan dapat menimbulkan hal-hal yang tidak diinginkan, 2). Dalam pelaksanaannya, tradisi Omed-omedan meripakan bagian dari Mesima Krama untuk menyambut Tahun Baru Caka. 3) makna dari pelaksanaan Omed-omedan ini adalah sebuah ketaatan terhadap Ida Bhatara Sesuhunan dimana dengan melaksanakan tradisi ini maka masyarakat akan tetap berada dalam lindunganNya.

Kata Kunci: Omed-omedan, Nyepi, Tradisi

\section{PENDAHULUAN}

Bali merupakan salah satu kepulauan di Indonesia yaitu terkenal sebagai daerah yang memiliki seni, budaya serta adat istiadat dan tradisi yang unik. Keunikan budaya di pulau ini merupakan kekayaan dari kebudayaan nasional/ nusantara yang memiliki kekhasan atau corak yang berbeda dengan corak kebudayaan daerah lainnya, sehingga menjadikannya terkenal di seluruh mancanegara. Selain itu Bali sebagai salah satu suku bangsa di Indonesia memiliki karakteristik seni dan budaya yang menarik bagi wisatawan mancanegara untuk berkunjung melihat perpaduan estetika (keindahan) budaya yang berdasarkan atas religiusitas Hinduisme, berdasarkan hal tersebut, Bali terkenal dengan berbagai julukan seperti : Pulau Sorga, Pulau
Seribu Pura, Pulau Pariwisata, dan lain sebagainya (Mantra, 1997 : 5).

Kebudayaannya adalah sarana untuk menerapkan dan mewujudkan ajaran agama Hindu di kepulauan nya. Agama Hindu di kepulauan ini adalah nafas kebudayaan Bali. Inti ajarannya adalah Sanatana Dharma, yaitu Satyam, Siwam, dan Sundaram , artinya Bali dibangun dengan cara menegakkan kebenaran dan kesucian yang dimiliki oleh budaya masyarakat, landasannya adalah keharmonisan dan keindahan serta dengan filsafat hidup yang berkesinambungan yang diwujudkan dalam kehidupan sehari-hari : berbakti terhadap Ida Sang hyang Widhi Wasa, bersahabat dengan sesama dan mencintai alam lingkungan berdasarkan yajna yaitu berkorban secara tulus ikhlas. Praktek seperti inilah yang sudah, sedang dan seharusnya dilaksanakan 
secara berkelanjutan pada hari-hari yang akan datang untuk mengajegkan Bali (Wiana, 2002 : 108).

Adanya tradisi pertunjukkan kebudayaan merupakan salah satu yang menjadi ciri khas masyarakat Bali. Sampai saat ini tradisi pertunjukkan tersebut masih tetap dilestarikan, karena hal tersebut adalah merupakan suatu warisan budaya dari para leluhur yang tidak boleh diabaikan begitu saja. Seperti halnya di Banjar Kaja Kelurahan Sesetan Kecamatan Denpasar Selatan, terdapat suatu jenis tradisi yaitu Tradisi Omed-omedan, tradisi ini senantiasa diadakan setiap satu tahun sekali yaitu pada hari ngembak geni atau tepatnya sehari setelah hari raya Nyepi.

Berdasarkan uraian latar belakang tersebut di atas, maka dapat dipaparkan permasalahan sebagai berikut. (1) Bagaimana proses pelaksanaan Tradisi Omed-omedan di Banjar Kaja Kelurahan Sesetan Kecamatan Denpasar Selatan?, (2) Bagaimana hubungan antara Tradisi Omed-omedan dengan rangkaian Hari Raya Nyepi di Banjar Kaja Kelurahan Sesetan Kecamatan
Denpasar Selatan?, (3) Apakah makna Tradisi Omed-omedan bagi masyarakat di Banjar Kaja Kelurahan Sesetan Kecamatan Denpasar Selatan?

\section{METODE PENELITIAN}

Pendekatan yang digunakan dalam penelitian ini adalah pendekatan kualitatif yang bersifat deskriptif analitis yaitu rancangan penelitian yang digunakan sebagai proses mengidentifikasi serta mendeskripsikan fenomena sosial yang terjadi di lapangan sebagaimana adanya. Kegiatan penelitian ini dilakukan di Banjar Kaje, Kelurahan Sesetan, Denpasar Selatan. Pengambilan sampel dalam penelitian dengan menggunakan teknik purposive non random sampling dimana sampel yang ada di lapangan dipilih sebagai informan dengan menentukan orang yang dipandang berkompeten dan mampu memberikan informasi yang diperlukan terkait dalam penelitian ini. Adapun pengumpulan data dilakukan dengan melalui observasi, wawancara, dokumentasi foto, dan bahan-bahan kepustakaan. 
HASIL PENELITIAN DAN PEMBAHASAN

Secara umum lazim keberadaan banjar (kelompokkelompok sosial) di Bali, Banjar Kaje termasuk wilayah Kelurahan Sesetan yang membawahi empat belas banjar yaitu banjar Kaje, banjar Tengah, banjar Pembungan, banjar Gaduh, banjar Puri Agung, banjar Lantang Bejuh, banjar Dukuh Sari, Alas Arum, Taman Suci, Taman Sari, banjar Pegok, Karya Dharma, banjar Suwung Batan Kendal, dan Kampung Bugis. Adapun ke empat belas banjar tersebut merupakan satu kesatuan antara Desa Adat dan Desa Dinas.Hal ini disebabkan karena Desa Adat Sesetan terdiri dari satu Desa Dinas.

Pelaksanaan upacara Omedomedan merupakan tradisi yang diwariskan secara turun-temurun di Banjar Kaje. Sebelum dilaksanakannya prosesi upacara itu, terlebih dahulu para pemuda-pemudi Banjar biasanya selalu mengadakan persembahyangan bersama di Pura Banjar tersebut dengan berbagai macam upakara yang di pimpin oleh Jero Mangku guna memohon ijin kehadapan Tuhan agar pelaksanaan
Omed-omedan berjalan dengan lancer tanpa hambatan-hambatan.

Menurut Kelihan Adat Banjar Kaja Sesetan, I Made Sukaja (wawancara tanggal 12 November 2014), sebelum pelaksanaan upacara Omed-omedan berlangsung, terlebih dahulu diadakan acara pembukaan dengan uraian singkat oleh Prajuru Banjar, Prajuru Banjar adalah orangorang yang berstatus sebagai pengurus Banjar yang terdiri atas Kelihan Banjar, Kelihan Dinas dan Ketua Sekaa Truna-Truni. Kedua Pejabat ini dimohonkan sebagai saksi dalam penyelenggaraan upacara Omed-omedan.

Setelah berakhirnya rangkaian persembahyang dan dharma tula dari Kelian Banjar, maka pada tahap selanjutnya, Kelihan Banjar memulai dengan membariskan para peserta Omed-omedan. Di satu sisi berdiri kelompok remaja laki/pria dan disisi lain (berhadapan) berdiri kelompok remaja putri/wanita. Nasehat singkat dan ucapan selamat melaksanakan Omed-omedan dititipkan kepada para peserta dan diharapkan upacara dapat berlangsung lancar, aman, dan damai. 
Pengawasan upacara Omedomedan diserahkan kepada petugas khusus sesuai dengan hasil rapat panitia. Setiap kelompok ditentukan jumlah anggotanya, untuk kelompok laki/pria berjumlah 40 orang, sedangkan kelompok perumpuan/wanita berjumlah 60 orang, perbedaan ini dimaksudkan agar kekuatan kedua kelompok menjadi seimbang. Untuk beberapa peserta yang belum mendapatkan bagian pada fase pertama dijadikan cadangan untuk masuk pada kelompok fase berikut dan demikian seterusnya, sehingga akhirnya semua anggota truna-truni yang hadir mendapat giliran masuk kelompok secara bergantian. Didalam permaianan pada tradisi tersebut, tiap-tiap fase ada kepala kelompoknya yaitu seseorang ditempatkan pada posisi paling depan, sedangkan anggota yang lain ada di belakangnya saling memegang/memeluk pinggang teman di depannya berbaris. Dengan demikian ada kepala kelompok untuk wanita/putri pada satu sisi dan ada kepala kelompok laki/putra-nya pada sisi lawannya.
Jikalau tanda permainan akan dimulai, kedua kelompok mulai saling berpegangan tangan yang diikuti pula oleh kelompoknya masing-masing. Pada saat upacara omed-omedan dimulai, petugas/ pecalang telah membagi diri menjadi tiga sub kelompok yaitu (1) sebagai petugas khusus, yang memberi tanda mulai dan berhentinya permainan, (2) sebagai petugas ketertiban yaitu mencegah permainan yang tidak disiplin termasuk penonton yang nakal, dan (3) penyiram air pertanda permainan fase awal berakhir.

Didalam proses permaian itu, tiap kepala kelompok berusaha menarik tangan lawannya ke-arah mereka masing-masing dengan dibantu oleh anggota kelompok lain yang memegang pinggang dari arah belakang dan terus menariknya kearah belakang sampai lawannya menyentuh/menginjak garis yang ditentukan petugas dan kelompok yang bersangkutan dinyatakan kalah. Kelompok yang dinyatakan kalah, harus menyerahkan kepala kelompoknya itu kepada kelompok yang menang. Yang diserahkan ini dinamakan sebagai pacundang. 
Pada tahap kedua, pacundang fase satu dijadikan jarahan kelompok yang menang pada fase pertama dan ditempatkan pada posisi satu atau kepala kelompok pada bekas lawannya pada fase satu. Pada fase kedua ini, jika ia menang berhadapan dengan bekas kawannya pada fase satu, maka pacundang ini mendapat tambahan pacundang lagi dari bekas kawannya lagi dan seterusnya. Jika terjadi hal yang sebaliknya, yaitu pada fase kedua ini ia kalah, maka pacundang ini kembali ke bekas kawannya seperti pada fase satu (seperti tahap awal tadi) dan demikian seterusnya.

Selain sebagai pemegang abaaba mulainya Omed-omedan, pecalang yang lain bertugas memisahkan pemain yang sedang bergulat berhadapan dengan lawannya untuk menghentikan suatu fase. Setiap siraman air oleh pecalang, peserta harus berhenti menarik lawan bermainnya. Siraman ini sebagai tanda penghentian fase.

Sesuai kesepakatan panitia dengan peserta upacara (anggota truna-truni), Omed-omedan akan berakhir jika peserta sudah mulai kelihatan letih, dan hari sudah menjelang sore, maka disanalah petugas akan menghentikan permainan upacara tersebut.

Hubungannya tradisi omedomedan dengan perayaan hari raya Nyepi, Menurut Kelihan Adat Banjar Kaje Sesetan, I Made Sukaja (wawancara tanggal 1 November 2014) tiada lain yaitu sebagai ajang masima krama dimana pada hari raya nyepi yang sering disebut dengan tahun baru caka anggota Banjar Kaje termasuk angota Truna-Truni diharapkan meningkatkan rasa persaudara (menyama braya) dikalangan seluruh warga anggota Banjar Kaje tersebut.

Senada dengan pernyataan diatas, I Made Munggah (wawancara tanggal 12 November 2014) sebagai Tokoh masyarakat, adapun menurut beliau upacara Omed-omedan merupakan Tradisi yang dilakukan secara turun temurun oleh warga Banjar Kaje Sesetan ini, disamping itu pula beliau menjelaskan bahwa tradisi ini disamping sebagai ajang masima krama, didalamnya termasuk memilliki nilai religius terkait Ida Betara Sesuhunan yang berstana di Pura Banjar Kaje. 
Penjelasan di atas diperkuat dengan pernyataan I Gusti Ngurah

Oka (wawancara tanggal 12 November 2014) sebagai Tokoh Adat yang juga merupakan salah seorang keturunan di Puri Oka Banjar Kaja, Kelurahan Sesetan,, beliau juga menjelaskan bahwa Tradisi Omed-omedan ini dimulai kurang lebih pada abad ke 17 yang berawal dari leluhurnya yang bernama Anak Agung Made Raka menjadi pemacuk (raja) mengatur pemerintahan di Desa Sesetan pada waktu itu. Pada saat menjelang Hari Nyepi, raja menderita sakit keras, walau sudah diobati ke berbagai dukun, tetapi tidak sembuh. Sehari setelah hari raya Nyepi masyarakat puri Oka menggelar permainan omed-omedan, saking antusiasnya suasana di depan puri sangat gaduh. Dengan berjalan terhuyun-huyun raja keluar dan melihat warganya yang sedang omed-omedan dan rangkulrangkulan. Kemudian terjadi keanehan ketika melihat masyarakatnya mengadakan permainan itu tiba-tiba raja tidak lagi merasakan sakit dan sehat seperti sedia kala.. Beliau kemudian bersabda mulai hari ini keramaian
Omed-omedan terus dilaksanakan setiap tahun sekali yaitu sehari setelah Hari Nyepi. Namun pemerintah Belanda waktu itu menjajah gerah dengan upacara tersebut, Belanda pun melarang ritual permainan itu. Warga akhirnya tidak menggelar omed-omedan, namun setelah permainan tidak lagi dilaksanakan tiba-tiba ada dua ekor babi besar berkelahi di tempat permainan biasa digelar. Akhirnya raja dan warga meminta petunjuk kepada leluhur, setelah itu kegiatan omed-omedan dilaksanakan kembali seperti sedia kala sebagai sebuah tradisi.

Dari pemaparan di atas dapat disimpulkan bahwa Tradisi Omedomedan memiliki hubungan yang erat dengan rangkaian hari raya Nyepi karena didalam pelaksanaannya diharapkan dapat meningkatkan rasa persaudaraan diantara warga Banjar Kaja, sebagai ajang masima krama.

Warga masyarakat pada umumnya selalu memberi makna kepada segala sesuatu yang ada didalam lingkungannya. Kecendrungn memberi makna itu merupakan aktifitas kolektif oleh 
seklompok masyarakat sesuai hal-hal yang dihadapinya. Menurut Ginddens, mengabstraksikan hasil pikiran kelompok masyarakat dan selanjutnya hasil itu berupa konsep, dan konsep tersebut kemudian menata kehidupan masyarakat yang bersangkutan sebagai nilai budaya. Selanjutnya nilai budaya merupakan abtraksi dari segala sesuatu yang dianggap bermakna tinggi dalam kehidupan suatu masyarakat (Purna, 2001: 144). Kearifan lokal yang terefleksikan dalam suatu upacara omed-omedan merupakan wujud dan abstraksi pikiran warga setempat sebagai suatu hal yang dianggap bermakna.

Adapun menurut Kelihan Adat Banjar Kaje, I Made Sukaja (wawancara tanggal 12 Novemberl 2014), implikasi makna dari tradisi Omed-omedan bagi masyarakat Banjar Kaje Kelurahan Sesetan Denpasar yaitu terbagi atas beberapa aspek yaitu :

1. Religi

$\begin{array}{lr}\text { Kearifan lokal yang tertuang } \\ \text { dalam upacara } & \text { Tradisi Med- } \\ \text { medan pada } & \text { hakikatnya } \\ \text { merupakan } & \text { salah } r \text { satu } \\ \text { perwujudan } & \text { aktivitas }\end{array}$

keagamaan dan emosi keagamaan yang dibangkitkan dengan adanya sesuhunan Ida Bhatara Petapakan yaitu Ida Ratu Ayu Mas Calonarang dan Ratu Gede Bangkal Putih di Pura Parerepan Banjar Kaja, Kelurahan Sesetan. Pura itu diyakini merupakan bangunan suci yang sakral bagi pemeluk Hindu di Banjar Kaja, Kelurahan Sesetan. Dalam konsep agama Hindu, berdoa atau sembahyang di tempat sakral seperti itu akan mendapatkan anygrah Ida Sanghyang Widhi.

\section{Solidaritas}

Dari segi makna solidaritas dapat dilihat yaitu masyarakat gotong royong yang menjunjung tinggi aspek kebersamaan dalam suka-duka yang sangat intens. Hampir semua tugas kemasyarakatan diselesaikan secara bersamasama, baik aktifitas sosial, ekonomi, maupun keagamaan. Demikian juga dalam upacara Tradisi Omed-medan semua warga banjar bergotong royong bekerja menyiapkan segala 
sesuatu dengan pemahaman yang sama, bahwa upacara itu untuk kepentingan seluruh warga banjar kaje. Dengan itu maka timbul kebersamaan dan warga selalu berusaha dalam kegiatan upacara tersebut untuk selalu memupuk kerukunan dan mewujudkan integrasi sosial secara nyata.

3. Budaya

Makna budaya bermatra budaya lokal Bali. Berbicara tentang budaya Bali asosiasi masyarakat Bali adalah filsafah Tri Hita Karana yang bernafaskan agama Hindu sebagai agama yang dianut oleh mayoritas masyarakat Bali dan sekaligus menjiwai kebudayaan Bali. di Bali, identitas budaya hampir selalu berhubungan dengan agama, sehingga makna budaya di sini tumpang tindih dengan makna agama. Masyarakat warga Banjar Kaja, Kelurahan Sesetan telah memahami, menghayati, dan menjalankan budaya leluhur, yaitu peka terhadap saudara atau tetangganya yang tersirat dalam istilah sagilik saguluk sabayantaka.

4. Kesejahteraan Pemahaman "makna kesejahteraan" hampir sama artinya dengan sentosa dan makmur, selamat/terlepas dari segala macam gangguan. Secara keseluruhan masyarakat warga Banjar Kaja, sampai saat ini mempercayai kesejahtraan yang mereka dapatkan tidak terlepas dari apa yang dilakukan warga yaitu berbakti terhadap Ida Bhatara Sesuhunan yang berstana di pura Parerepan dengan melaksanakan upacara omedomedan.

\section{Simpulan}

1. Masyarakat di lingkungan Banjar Kaja Sesetan mempunyai suatu warisan budaya lokal yaitu Tradisi Omed-omedan yang sejak jaman penjajahan Belanda sudah ada dan pelaksanaannya berproses hingga saat ini masih tetap berlanjut dijaga oleh 
generasi penerus sebagai masyarakat pendukungnya.

2. Dalam Pementasannya Tradisi Omed-omedan merupakan ajang masima krama dalam rangka menyambut tahun baru saka, setelah hari raya Nyepi yaitu yang disebut dengan Ngembak Geni. Beranjak dari hal tersebut maka Tradisi Omed-omedan memiliki suatu fungsi-fungsi sebagai berikut yaitu mulai dari aspek religi, solidaritas, budaya, hingga aspek kesejahteraan masyarakat di lingkungan Banjar Kaja Kelurahan Sesetan Denpasar.

\section{Tradisi}

Omed-omedan merupakan Purwa Dresta yaitu kebiasaan-kebiasaan yang bersifat religius yang diyakini akan memberikan kesejahteraan bagi masyarakatnya. Tradisi ini bermakna sakral terkait dengan Ida Bhatara Sesuhunan yang berstana di Pura Pererepan Banjar Kaje, yang senantiasa dipentaskan oleh Sekaa Truna Truni dalam hubungannya dengan upacara omed-omedan.

\section{Saran}

1. Kepada Masyarakat Banjar Kaja Sesetan Denpasar agar selalu senantiasa menjaga dan melestarikan tradisi yang telah diwariskan oleh leluhur dan terus mempertahankannya dari berbagai pengaruh budaya asing sehingga Tradisi Omedomedan tetap sebagai tradisi yang bernilai sakral.

2. Kepada truna-truni Banjar Kaje sebagai pendukungnya agar tetap melestarikan Tradisi Omed-omedan sehingga di dalam pelaksanaan nya akan selalu berpedoman pada nilai religius dari kebudayaan tersebut.

3. Kepada Departemen Agama , PHDI, dan Instansi yang terkait agar selalu memberikan penyuluhanpenyuluhan agama terutama yang berkaitan tentang tradisi sakral sehingga seluruh umat Hindu selain yang ada di 


\begin{abstract}
banjar Kaje sesetan
senantiasa memelihara dan

menjaga kesucian setiap

tradisi sakral yang ada di

desanya masing-masing agar

tradisi yang ada tetap lestari.
\end{abstract}

\title{
DAFTAR PUSTAKA
}

Mantra, I. B. 1997. Landasan Kebudayaan Bali. Denpasar: Yayasan Dharma Sastra.

Wiana, I K. 2002. Memelihara Tradisi Veda. Denpasar: Pustaka Bali Post. 